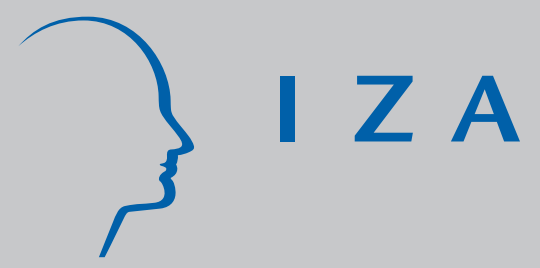

IZA DP No. 1190

Labour and Product Market Reforms:

A Case for Policy Complementarity

Bruno Amable

Donatella Gatti

J une 2004 


\title{
Labour and Product Market Reforms: A Case for Policy Complementarity
}

\author{
Bruno Amable \\ University of Paris $X$ - Nanterre \\ and CEPREMAP \\ Donatella Gatti \\ University of Lyon 2, \\ CEPREMAP and IZA Bonn
}

\section{Discussion Paper No. 1190 June 2004}

\author{
IZA \\ P.O. Box 7240 \\ 53072 Bonn \\ Germany \\ Phone: +49-228-3894-0 \\ Fax: +49-228-3894-180 \\ Email: iza@iza.org
}

Any opinions expressed here are those of the author(s) and not those of the institute. Research disseminated by IZA may include views on policy, but the institute itself takes no institutional policy positions.

The Institute for the Study of Labor (IZA) in Bonn is a local and virtual international research center and a place of communication between science, politics and business. IZA is an independent nonprofit company supported by Deutsche Post World Net. The center is associated with the University of Bonn and offers a stimulating research environment through its research networks, research support, and visitors and doctoral programs. IZA engages in (i) original and internationally competitive research in all fields of labor economics, (ii) development of policy concepts, and (iii) dissemination of research results and concepts to the interested public.

IZA Discussion Papers often represent preliminary work and are circulated to encourage discussion. Citation of such a paper should account for its provisional character. A revised version may be available on the IZA website (www.iza.org) or directly from the author. 
IZA Discussion Paper No. 1190

June 2004

\section{ABSTRACT}

\section{Labour and Product Market Reforms: A Case for Policy Complementarity*}

This paper is a contribution to the debate on policy complementarity in relation to deregulation in the product and labour markets. We develop a model of dynamic efficiency wages and monopolistic competition. Whereas most of the literature points toward the gains associated to an increase in product market competition coupled with an increased flexibility of the labour market, we show that even when more product market competition is the policy recommendation, it should be accompanied by an increase in job security.

JEL Classification: E24, J41, J63, L13

Keywords: policy complementarity, job protection legislation, efficiency wage, imperfect competition

Corresponding author:

Donatella Gatti

CEPREMAP

142 rue de Chevaleret

75013 Paris

France

Email: donatella.gatti@cepremap.cnrs.fr

\footnotetext{
* The authors would like to thank Torben Andersen, Giovanni Dosi, Alfonso Gambardella and David Soskice for helpful remarks on previous versions of the paper. The usual caveats apply.
} 


\section{Introduction}

This paper is a contribution to the current debate on the issue of the interplay of institutions in product and labour markets as well as the related debate on policy complementarity.

This debate finds its origins in the comparison between the respective performance of Europe and the USA and the diagnostic of 'eurosclerosis'. The argument most widely found in the literature is that the level of employment protection in European labour markets hinder the proper functioning of these markets, making them 'inflexible'. ${ }^{1}$ This yields important constraints on firms operation, which make them less productive. Moreover, product market regulation makes firms selection through competition less efficient. The consequences in terms of employment, aggregate production and, one may suppose, growth are strongly negative. Since too much rigidity is detrimental to performance, the obvious policy recommendations are to remove obstacles to flexibility: decrease unemployment benefits, abolish job protection legislation, increase mobility of labour, improve product market competition... ${ }^{2}$

Recent papers ${ }^{3}$ have argued that removing obstacles to a flexible labour market may be more complicated than it seems because the various sources of rigidity are complementary to each other: unemployment benefits discourage unemployed from seeking employment while firing costs discourage firms from offering jobs to the unemployed. Therefore, the individual effects of each rigidity is magnified by the presence of other rigidities. This case of complementarity makes partial labour market reform unlikely to achieve any significant reductions in the unemployment rate, but very 
likely to be met with active political opposition from those who lose from the reform. Therefore, because of policy complementarity, fundamental rather than partial labour market reform should be undertaken, with an aim to lower labour market rigidities all at once.

This debate on policy complementarity has been recently revisited with the consideration of product market reforms. ${ }^{4}$ Deregulation both in labour and product markets should be expected to have joint effects on the employment level that exceed the separate effects that deregulation in each market could have when implemented alone. Product market deregulation should increase competition and thus bring about an outward shift of the labour demand curve of each firm. On the other hand, labour market deregulation should affect both labour demand and labour supply curves and lead to a decrease in unemployment. The policy recommandations are here again clear: one should increase competition on the product markets side and decrease employment protection on the labour market side. The combination of both policies will make the implementation of each one easier to accept by lowering the costs and increasing the benefits of ajustment on both markets.

This paper challenges this view by showing that policy complementarity may lead to recommend to increase employment protection while increasing product market competition when one seeks to decrease the unemployment rate. In some cases, the competition policy necessary to increase employment may even call for a decrease in product market competition.

We consider a model of dynamic efficiency wages combined with monopolistic competition on the product markets side. We further consider that the economy is 
subject to production shocks, Good or Bad, which force some firms to adapt their labour force to the new business conditions, generating an endogenous labour market turnover. Labour mobility means that workers must be indifferent across the two options of working in firing or hiring firms, which generates a positive wage differential across firms in different states. At the same time, due to the monopolistic competition assumption, productivity differentials across firms are (partially) translated into price differentials across type- $B$ and type- $G$ firms: this contributes to smoothing employment differentials across firms in different states, thus reducing the size of workers flows as a response to demand and/or productivity shocks. Furthermore, workers made redundant obtain a lump-sum compensation paid by the firm where they worked. This firing cost makes firms less willing to lay off workers when experiencing a bad shock.

We show that firing costs decrease labour turn-over and therefore tend to lower the efficiency wage premium ${ }^{5}$, while increased product market competition does the opposite. This enlightens the existence of functional complementarity across labour and product markets: changing product market structure bears immediate consequences on the operation of the labour market. Depending on the relative impact on job creation and job destruction, product market competition may either increase or decrease unemployment. In order to increase the chances that product market competition improves the employment performance of the economy, the complementary policy is not to lower employment protection but to increase it in order to foster the job creation effects of competition rather than the job destruction effect.

The paper is organised as follows: section 2 presents the model with the efficiency 
wage mechanism and monopolistic firms' labour demand. Section 3 establishes the conditions for the existence of a unique equilibrium. Section 4 discusses the separate effects of product market competition and employment protection on labour turnover. It is shown that increased product market competition may increase or decrease the level of employment. An increase in employment protection may then have complementary or offsetting effects. The last section briefly concludes.

\section{The model}

We consider an economy with a single final good used for consumption and a continuum of intermediate goods indexed over $[0,1]$. The final good is produced competitively, but there is monopolistic competition on the intermediate goods market: each firm is small compared to the economy but has a monopoly power within its sector. The final good production function is the following:

$$
\widetilde{Y}_{t}=\left(\int_{0}^{1} Y_{t}(j)^{\frac{\eta-1}{\eta}} d j\right)^{\frac{\eta}{\eta-1}}
$$

with $\eta>1$. Such a specification leads to a derived demand addressed to firm $j$ equal to:

$$
Y_{j}=\left(\frac{P_{j}}{P}\right)^{-\eta} \cdot \widetilde{Y}
$$

where $P_{j}$ is the price of intermediate $j$ and $P$ is the final good's price. One further has:

$$
P=\left(\int_{0}^{1} P_{j}^{1-\eta} d j\right)^{\frac{1}{1-\eta}}
$$


Each firm $j$ has an identical production function which uses labour as its sole input: $Y_{j t}=\alpha_{j t} \cdot l_{j t}$ with $0<\gamma \leq 1, l_{j}$ is the input of effective labour, i.e. $l_{j}$ workers providing the expected effort level.

Firms are subject to 'productivity' shocks which can be thought as stemming from fluctuations in factors other than labour or from a varying technological efficiency. We adopt the same shock specification as Bertola [1990], Bertola and Ichino [1995] or Bertola and Rogerson [1997]. The shock's realisations are denoted $\alpha_{j t}$ for firm $j$ at time $t$, they are independent across firms. More specifically, the $\alpha$ s follow a two-state Markov chain with symmetric transition probability $p$ :

$\alpha_{j t+1}=\left\{\begin{array}{c}\alpha_{G} \text { with probability } p \text { if } \alpha_{j t}=\alpha_{B} \text { and with probability } 1-p \text { if } \alpha_{j t}=\alpha_{G} \\ \alpha_{B} \text { with probability } 1-p \text { if } \alpha_{j t}=\alpha_{B} \text { and with probability } p \text { if } \alpha_{j t}=\alpha_{G}\end{array}\right.$

and $\alpha_{G}>\alpha_{B}>0$. We further assume some degree of 'persistence' in the shocks' realisation: $p<1 / 2$.

There are thus two states for the technology: a 'good' state $G$ with a high labour productivity, and a 'bad' state $B$ with a low value for labour productivity. The longrun probability for a given firm to be in either a good or a bad state is 0.5 . In what follows, we will then assume that at each time $t, 50 \%$ of the firms are in the good state while $50 \%$ are in a bad state. ${ }^{6}$ Therefore, there will be no aggregate fluctuations in either output or employment. 


\section{$2.1 \quad$ wage setting}

The economy is populated with a fixed number $N$ of agents who supply labour inelastically. Each individual worker is characterised by an identical utility function, where instantaneous utility depends on the real wage ${ }^{7}$ and on the effort provided on the job:

$$
u_{t}=w_{t}^{i}-e_{t}
$$

$i=G, B ; e_{t}$, the effort level, can take two values, 0 , which means that the worker is 'shirking' and $e$, which means that the worker provides the expected work effort. The contribution of a shirker to effective labour is nil, whereas an individual working with the expected effort level $e$ contributes for one unit to effective labour. $w_{t}^{i}$ is the real wage. Each firm has a monitoring device that allows to detect a shirking worker with probability $x_{t}$. The probability of getting away with shirking is thus $1-x_{t}$. A worker who is caught shirking immediately loses his job. This simple specification and will allow us to consider an efficiency wage model in the spirit of Shapiro and Stiglitz [1984] or Saint-Paul [1996].

We enrich the basic setup of the efficiency wage models, by considering an additional source of job loss: ${ }^{8}$ firms are subject to shocks which affect their productivity and force them adjust their labour force. If $l_{G}\left(l_{B}\right)$ is employment of a representative firm in a good (bad) state and we denote $q_{t}$ the probability of losing one's job 
following an adverse shock, then:

$$
q_{t}=\frac{l_{G t}-l_{B t}}{l_{G t}}=\left(1-\frac{1}{l_{t}}\right)
$$

with $l=\frac{l_{G t}}{l_{B t}}$.

Workers have an infinite horizon and discount future at the rate $r$. As mentioned before, workers employed in a firm hit by a bad productivity shock face a probability $q$ of losing his job since workers are laid off randomly. When a worker actually loses his position because of labour force adjustment, he receives a lump sum $F$ as compensation. This sum is paid by the firm which lays off workers. On the other hand, a worker fired because he was caught shirking receives nothing.

We can now compute the discounted utilities associated with the various possible positions for an individual: being employed in a type- $G$ or a type- $B$ firm and shirking or not shirking, or being unemployed. The discounted utility of a worker who shirks at time $t$ in a type- $G$ firm is $V_{S t}^{G}$, and $V_{N S t}^{G}$ when he does not shirk. The utilities associated to working in a type- firm are likewise $V_{S t}^{B}$ (shirking) and $V_{N S t}^{B}$ (not shirking). The utility of being unemployed is $U_{t}$. We then have:

$$
\begin{aligned}
r \cdot U_{t} & =a \cdot\left(V_{t}^{G}-U_{t}\right) \\
r \cdot V_{S t}^{G} & =w_{t}^{G}+x \cdot\left(U_{t}-V_{S t}^{G}\right)+p \cdot q \cdot\left(U_{t}+F-V_{S t}^{G}\right)+p \cdot(1-q) \cdot\left(V_{t}^{B}-V_{S t}^{G}()^{8}\right) \\
r \cdot V_{N S t}^{G} & =w_{t}^{G}-e+p \cdot q \cdot\left(U_{t}+F-V_{N S t}^{G}\right)+p \cdot(1-q) \cdot\left(V_{t}^{B}-V_{N S t}^{G}\right) \\
r \cdot V_{S t}^{B} & =w_{t}^{B}+x \cdot\left(U_{t}-V_{S t}^{B}\right)+p \cdot\left(V_{t}^{G}-V_{S t}^{B}\right) \\
r \cdot V_{N S t}^{B} & =w_{t}^{B}-e+p \cdot\left(V_{t}^{G}-V_{N S t}^{B}\right)
\end{aligned}
$$


$V_{t}^{B}$ and $V_{t}^{G}$ are equilibrium levels associated with working in a $B$-firm and in a $G$-firm respectively.

The level of real wage in each firm must be set at a level such that workers have an incentive not to shirk. These no-shirking conditions are

$$
V_{N S t}^{j} \geq V_{S t}^{j}
$$

By imposing the no-shirking conditions, one obtains: ${ }^{9}$

$$
V^{G}=V^{B}
$$

which ensures that workers are indifferent between working in a type- $G$ firm and working in a type- $B$ firm. The conditions $V_{N S t}^{i}=V_{S t}^{i}=V_{t}^{i}, i=G, B$ give the two limit wage levels $w_{i t}^{G}\left(w_{i t}^{B}\right), w_{i t}^{B}\left(w_{i t}^{G}\right)$ under which the optimal behaviour for the worker is to shirk. Since we are dealing with constant values for all variables at the steady-state equilibrium, we may dispense with the time subscripts from now on. Both $w_{i}^{G}\left(w_{i}^{B}\right)$ and $w_{t}^{B}\left(w_{i}^{G}\right)$ are affine functions. Solving $w_{e}^{G}\left(w_{B}\right)=w_{i}^{G}\left(w^{B}\right)$ and plugging into $w_{i}^{B}\left(w^{G}\right)$ give the equilibrium values for $w^{B}$ and $w^{G}$ :

$$
\begin{aligned}
w^{G} & =\frac{a+p \cdot q+r+x}{x} \cdot e-F \cdot p \cdot q \\
w^{B} & =\frac{a+r+x}{x} \cdot e
\end{aligned}
$$

Both wages can be understood as a mark-up over $e$, the cost of effort. This mark- 
up is larger when the opportunity of finding a job when unemployed is higher because of the negative incentive effect that this opportunity exerts on an employed worker. The mark-up decreases with $x$,the efficiency of the firm's monitoring of individual effort. It increases with $r$, the discount rate. The probability of losing one's job because of labour adjustment concerns workers employed in $G$-firms only. Therefore, $q$ is only present in the expression for $w^{G} \cdot \frac{\partial w^{G}}{\partial q}$ has the sign of $\frac{e}{x}-F$. The wage rate for employees of a $G$-firm increases with job insecurity (for effort-incentive reasons) when the cost of effort is high, effort monitoring difficult and when the redundancy indemnity is moderate.

\section{2 labour demand}

We now turn to the hiring and firing decisions of the firms. For each firm, the value of a marginal worker $J$ must satisfy a condition such as: $r \cdot J=\frac{\partial \pi}{\partial l}-C+E[\dot{J}]$, where

$\frac{\partial \pi}{\partial l}$ is the marginal revenue, $C$ a fixed cost and $E[\dot{J}]$ the expected change in $J$. We must distinguish between the value of a marginal worker in a $G$-firm, $J_{G}$, and that in a $B$-firm, $J_{B}$. A firm hit by a bad shock will adjust its labour force up to the point where the value of the marginal worker is equal to minus the redundancy indemnity, which is the dismissal cost: $J_{B}=-F$. Therefore, the value of the marginal job for a $B$-firm satisfies 15 , where $J_{G}+F$ is the change in the value of the job and $p$ the probability of switching from $B$ to $G$. The value of a job in a $G$-firm must satisfy the second equation. 


$$
\begin{aligned}
-r \cdot F & =\frac{\partial \pi_{B j}}{\partial l_{B j}}+p \cdot\left(J_{G}+F\right) \\
r \cdot J_{G} & =\frac{\partial \pi_{G j}}{\partial l_{G j}}-p \cdot\left(J_{G}+F\right)
\end{aligned}
$$

Opening a new job is costless, therefore $G$-firms will increase employment up to the point where $J_{G}=0$. Therefore, $\frac{\partial \pi_{B j}}{\partial l_{B j}}+(p+r) \cdot F=0$ and $\frac{\partial \pi_{G j}}{\partial l_{G j}}-p \cdot F=0$. According to the state $j$ of the firm, the marginal revenue is given by

$$
\frac{\partial \pi_{j}}{\partial l_{j}}=\frac{P_{j}}{P} \cdot\left(1+\frac{\partial P_{j}}{\partial l_{j}} \cdot \frac{l_{j}}{P_{j}}\right)-w^{j}-\frac{\partial w^{j}}{\partial l_{j}} \cdot l_{j}
$$

where $w_{j}$ is the real wage paid by firm $j$.

Because firms have market power within their sector, the price of intermediate vary across type $-G$ and type $-B$ firms: we denote it respectively $P_{G}$ and $P_{B}$. We normalise $P=1$. Using the above expression for $\frac{\partial \pi_{j}}{\partial l_{j}}$, we can rewrite (15) as follows:

$$
\begin{aligned}
\alpha_{G} \cdot P_{G} \cdot\left(1-\frac{1}{\eta}\right) & =w^{G}+p \cdot\left(\frac{e}{x}-F\right) \cdot(1-q)+p \cdot F \\
& =\frac{a+p+r+x}{x} \cdot e \\
\alpha_{B} \cdot P_{B} \cdot\left(1-\frac{1}{\eta}\right) & =w^{B}-(p+r) \cdot F \\
& =\frac{a+r+x}{x} \cdot e-(p+r) \cdot F
\end{aligned}
$$

The two first-order conditions relate the price of intermediate goods (relative to the price index $P$ ) to the real wage level in each sector of the economy. From the price index (3) and aggregate production, one can derive the expression for intermediate 
goods' prices. We can denote $Y_{B}$ as total output of firms in a bad state and $Y_{G}$ is total output of firms in a good state; likewise employment is respectively given by $L_{B}$ and $L_{G}$. As within the economy at any given time, there will be half of the firms in a bad state and half of the firms in a good state, from (1) one obtains that $\widetilde{Y}_{t}=\left(\int_{0}^{1} Y_{t}(s)^{\frac{\eta-1}{\eta}} d s\right)^{\frac{\eta}{\eta-1}}=\left(\frac{1}{2} \cdot Y_{B}^{\frac{\eta-1}{\eta}}+\frac{1}{2} \cdot Y_{G}^{\frac{\eta-1}{\eta}}\right)^{\frac{\eta}{\eta-1}}$. Since $Y_{s}=P_{s}^{-\eta} \cdot \widetilde{Y}$, defining $\alpha=\frac{\alpha_{G}}{\alpha_{B}}$ one has:

$$
\begin{aligned}
& P_{B}=\left(\frac{1+(\alpha \cdot l)^{\frac{\eta-1}{\eta}}}{2}\right)^{\frac{1}{\eta-1}} \\
& P_{G}=\left(\frac{1+(\alpha \cdot l)^{\frac{1-\eta}{\eta}}}{2}\right)^{\frac{1}{\eta-1}}
\end{aligned}
$$

Moreover, an expression for the relative price of intermediates $\frac{P_{B}}{P_{G}}$ can also be derived from the demand curves (2). One easily obtains:

$$
\frac{P_{B}}{P_{G}}=\left(\frac{Y_{G}}{Y_{B}}\right)^{\frac{1}{\eta}}=(\alpha \cdot l)^{\frac{1}{\eta}}
$$

Firms in the intermediate sectors earn positive profits at the equilibrium. However, these profits clearly vanish as competition increases that is as the price elasticity of demand within each industry rises (we will come to this point in section 4). ${ }^{10}$

\section{Macroeconomic equilibrium}

At any time $t$, half of the firms are exposed to a favourable shock while the other half are exposed to a bad shock: a fraction $p$ of the type- $G$ firms switch positions 
with a fraction $p$ of the type- $B$ firms. The formerly type- $G$ turned type- $B$ firms have to shed labour in order to adjust their labour force to its optimal value, while formerly type- $B$ now type- $G$ firms need to make the opposite adjustment. Laid-off workers join the ranks of the unemployed while some unemployed workers find new employment with firms having switched from $B$ to $G$. At the steady state equilibrium, the unemployment rate stays constant and the flows in and out of unemployment balance each other out. Recalling that $a$ is the flow probability out of unemployment, one has:

$$
a \cdot\left(N-\frac{L_{G}+L_{B}}{2}\right)=\frac{p}{2} \cdot q \cdot L_{G}
$$

Since we know that $L_{G}=\frac{L_{B}}{1-q},(23)$ allows us to define aggregate employment as a function of the separation and hiring rates. Hence, we can solve the model by deriving the equilibrium values of the latter two endogenous variables.

One can show that the first-order conditions (18) and (19) define the equilibrium value of the employment ratio of type- $G$ to type- $B$ firms as well as the hiring rate. This will allow us to define the level of employment and wages in firms of either type.

First, it must be observed that combing the two price setting equations (18) and (19), one has

$$
\frac{P_{B}}{P_{G}}=\frac{\alpha \cdot \varphi^{B}}{\varphi_{G}}
$$

with $\varphi^{B} \equiv \frac{a+r+x}{x} \cdot e-(p+r) \cdot F$ and $\varphi_{G} \equiv \frac{a+p+r+x}{x} \cdot e$.

Then, using (22) to substitute for $\frac{P_{B}}{P_{G}}$, one can easily rewrite (24) to obtain $\frac{a+r+x-\frac{x}{e} \cdot(p+r) \cdot F}{a+p+r+x} \cdot \alpha=(\alpha \cdot l)^{\frac{1}{\eta}}$. This defines a first expression for relative employment $l$ that we denote: 


$$
l(a, \eta, F)=\left[\alpha^{\frac{\eta-1}{\eta}} \cdot\left(1-\frac{e \cdot p+x \cdot(p+r) \cdot F}{e \cdot(a+x+r+p)}\right)\right]^{\eta}
$$

One can show that $\frac{\partial l}{\partial a}>0, \frac{\partial l}{\partial \eta}>0, \frac{\partial l}{\partial F}<0$. We develop in Appendix 1 a formal analysis to establish the uniqueness of the macroeconomic equilibrium. What we would like to stress here is that equation (25) indicates that increased product market competition yields a modification in the structure of the labour market, i. e. larger employment differentials across firms. Severance payments appear to have the opposite effect. Moreover, policies leading to labour market activation through more intense hiring also affect employment differentials across firms. Building on this, we can now move on to the analysis of the consequences of increased product market competition and firing costs on the labour market operation.

\section{An analysis of policy complementarity}

\section{1 functional complementarity across labour and produt mar- ket}

This section investigates the effects of changes in the variable characterising product market competition, $\eta$, and that characterising job protection. The results are described in the following proposition.

Proposition 1 An increase in $\eta(F)$ always raises (reduces) the separation rate $q$.

Proof. See Appendix 1 
This proposition establishes that an increase in product market competition unambiguously raises labour market turnover and job insecurity. An intuitive rationale for this result is the following. The switch between $G$ - and $B$-type will force firms to adjust, and this adjustment will be all the more sizeable that competition reduces profit margins at the equilibrium. The adjustment could be a price adjustment or a quantity (labour) adjustment. The former type of adjustment is somehow constrained by the effort incentive conditions and the pricing behaviour it induces. Increased product market competition reduces relative prices $\frac{P_{B}}{P_{G}}$. Therefore, firms have to resort to quantity adjustments in a larger proportion. The effect of the firing cost (redundancy payment) is more in line with the traditional results of the literature. ${ }^{11}$ By making labour shedding more costly, firing costs decrease the incentives to lay off workers and thus reduce turnover. Therefore, redundancy payment $F$ acts as an employment protection device.

Product market competition and firing costs also influence the hiring side of the labour market. Results concerning hiring are established in the next proposition.

Proposition 2 An increase in $\eta$ or $F$ always raises the probability of finding a job when unemployed.

\section{Proof. See Appendix 1}

This result expresses the positive effect of product market competition, which gives more job opportunity to the unemployed. However, employment protection too has a positive impact on job opportunities. 
The above propositions show that more competition on the product market yields more turnover on the labour market. There are two main consequences from this result.

First, increased competition makes the burden of adjustments that falls on employment heavier. Depending on the relative elasticities of the separation and hiring rates to an increase in product market competition, this may ultimately lead to aggregate employment losses. In fact, while the effects of job protection are favorable to employment since it increases hiring and reduces firing, the effects of product market competition are more ambiguous. More competition improves the expectations of the unemployed of finding employment, but it also increases the probability of losing it once employed. The net effects of competition on employment cannot therefore be simply deduced.

Second, the above results stress the existence of a tight link between the way the labour and product markets operate. In this sense, one might argue that there exists a functional complementarity across the two markets: the structures of the two markets are complementary and need to be analyzed jointly. Moreover, one should note that engaging in a process of product market deregulation yields an "implicit labour market reform". This point leads us to the crucial question of policies complementarity.

\section{2 complementarity across policies}

This section investigates changes in the economic equilibrium following a change in both product market competition and employment protection. This is precisely the 
type of policy recommendation that institutions such as the OECD are advocating.

When taken separately, both $\eta$ and $F$ have an effect on employment. The effect of the former parameter is ambiguous. On the whole, increased product market competition increases both flows in and out of employment, which means that total employment may decrease if the former effect predominates. ${ }^{12}$ In fact:

$$
\frac{d L}{d \eta}=\frac{\partial L}{\partial l} \cdot \frac{\partial l}{\partial \eta}+\frac{\partial L}{\partial a} \cdot \frac{\partial a}{\partial \eta}
$$

with $\frac{\partial L}{\partial l}<0$ and $\frac{\partial L}{\partial a}>0$.

Total employment increases with the hiring rate and decreases with the firing rate. Therefore $\frac{d L}{d \eta}>0$ if

$$
\frac{-L_{l}}{L_{a}}<\frac{a_{\eta}}{l_{\eta}}
$$

where $X_{x}=\frac{\partial X}{\partial x}$. One should further note that $\frac{a_{\eta}}{l_{\eta}}<1$.

Can the possible negative impact of increased competition on employment be offset by a policy measure concerning employment protection? Since the effects of the redundancy indemnity are unambiguously positive for employment, one may reasonably expect that more employment protection should somehow reduce the possible adverse effects of product market competition. This possible complementarity can be established in two ways:

- through the analysis of cross-derivatives: increased competition is more effective in improving employment and welfare when firing costs are higher; 
- by comparing two alternative policy packages and show that $\{\eta, F\}$ dominates $\{\eta, 0\}$ in terms of employment and welfare.

Concerning this latter point, from what was said before, one can see that:

$$
\begin{aligned}
& a^{*}(\eta, F)>a^{*}(\eta, 0) \\
& l^{*}(\eta, F)<l^{*}(\eta, 0)
\end{aligned}
$$

This proves that a policy package associating higher competition and employment protection is always dominant from the point of view of improving macroeconomic performance i.e. employment.

As for the cross-derivatives analysis, although it is not possible to obtain clear-cut results on the sign of $\frac{\partial^{2} L}{\partial \eta \partial F}$, we shall nevertheless show that higher firing costs reduce the 'negative' impact of competition on turnover, that is firing costs help moderating the wrong side-effects of competition on the firing rate.

We show in Appendix 2 that $\frac{\partial^{2} a}{\partial \eta \partial F}<0$ and $\frac{\partial^{2} l}{\partial \eta \partial F}<0$. By denoting $|x|$ the variable's absolute value, one can also show that:

$$
\left|\frac{\partial^{2} l}{\partial \eta \partial F}\right|>\left|\frac{\partial^{2} a}{\partial \eta \partial F}\right|
$$

These results suggest that increasing firing costs offers a way to positively "bias" the effects of increased competition in favour of more hiring rather than more firing. Higher firing costs lower the "reactivity" of the separation and hiring rates to product market competition. This effect is prooved to be stronger for the former than for the 
latter - i.e. following equation (28) one should expect to observe a relatively bigger decrease in $l_{\eta}$ than in $a_{\eta}$. We can see that this corresponds to an increase in $\frac{a_{\eta}}{l_{\eta}}$, which makes condition (27) more easily met: when firing costs increase, competition more easily leads to a positive outcome in terms of employment.

This suggests a case for policy complementarity between employment protection and product market competition which is different from the usual policy prescriptions. Increased competition in product markets should not be accompanied by less but by more employment protection.

A complete characterisation of the possible cases where the conditions above are met would be extremely difficult to undertake. Some examples are however presented in Appendix 2, where a calibration is proposed showing that increased competition indeed has a negative impact on employment and welfare. The clear negative impact of product market competition on employment and welfare is achieved with a relatively small difference between $\alpha_{B}$ and $\alpha_{G}$. Increasing the redundancy indemnity always improves the situation, limiting the detrimental effects of competition on employment. In the second example, with a higher difference between $\alpha_{B}$ and $\alpha_{G}$, competition increases employment and welfare. We are thus in the more traditional case, featured in most of the literature on the topic. However, even in this case, policy complementarity calls for more employment protection. 'Deregulation' of the labour market would imply diminishing the benefits of increased product market competition instead of augmenting them. 


\section{Conclusion}

This paper has investigated the links between product market competition and labour market imperfections with the help of a simple model of monopolistic competition and dynamic efficiency wages with firing costs. We were thus able to analyse the joint effects of an increase in product market competition and labour market 'deregulation'. Whereas the bulk of the literature on the topic advocates 'deregulation' in both markets, our conclusion is that increased competition will eventually improve employment and welfare if a suitable policy for employment protection is in place, that is not in spite of but rather owing to the existence of non negligible firing costs.

Our results come from the specification of the labour market imperfection that was adopted here. Our model is able to incorporate the fact that employment insecurity may push wages up in spite of agents' risk-neutrality. Efficiency wages put some constraints on price adjustments, which forces firms to resort more to quantity adjustments, which in turn exert a direct effect on wages. This influence may be exacerbated by increased competition but is dampened by firing costs. Therefore, a policy of increased job security may be necessary to offset the possible detrimental effects of increased product market competition. 


\section{References}

[1] Amable B. and Gatti D. [2004] Product market competition, job security and aggregate employment, Oxford Economic Papers, forthcoming.

[2] Bertola G. [1990] Job security, employment and wages. European Economic Review $34,851-886$.

[3] Bertola G. and Ichino A. [1995] Wage Inequality and Unemployment: United States vs. Europe. In: Bernanke B. and Rotemberg J. (Eds) NBER Macroeconomics Annual 1995.

[4] Bertola G. and Rogerson R. [1997] Institutions and labor reallocation. European Economic Review 41, 1147-1171.

[5] Blanchard O., Giavazzi F. [2003] Macroeconomic effects of regulation and deregulation in goods and labor markets, Quarterly Journal of Economics, August, 879-907.

[6] Boeri T., Nicoletti G. and Scarpetta S. [2000] Regulation and labour market performance. CEPR Discussion Paper No. 2420, April.

[7] Coe D. and Snower D. [1997] Policy Complementarities: the case for fundamental labour market reform. CEPR Discussion Paper No.1585.

[8] Fella G. [2000] Efficiency wage and efficient redundancy pay, European Economic Review, 44, 1473-1491. 
[9] Gersbach H. [2000] Promoting Product Market Competition to Reduce Unemployment in Europe: An Alternative Approach?. Kyklos, 53(2), 117-133.

[10] Gersbach H. [1999] Product Market Competition, Unemployment and Income Disparities. Weltwirtschaftliches Archiv, 135(2), 221-240.

[11] Nickell S. [1999] Product markets and labour markets. Labour Economics, 6(1), $1-20$.

[12] Nickell S. [1997] Unemployment and Labour Market Rigidities: Europe versus North America. Journal of Economic Perspectives, 11(3) 55-74.

[13] Nicoletti G., Haffner R.C.G., S. Nickell, S. Scarpetta and G. Zoega [2000] European Integration, Liberalisation and labor Market Performance. In: Bertola G., T. Boeri and G. Nicoletti (Eds) Welfare and Employment in a United Europe. MIT Press.

[14] OECD [1994] Jobs Strategy, Paris: OECD.

[15] OECD [1997] Employment Outlook. Paris: OECD.

[16] Orszag M. and Snower D. [1998] Anatomy of policy complementarities. CEPR Discussion Paper No. 1963.

[17] Saint-Paul G. [1996] Dual Labor Markets. Cambridge: MIT Press.

[18] Saint-Paul G. [2000] The political economy of labour market institutions. Oxford: Oxford University Press. 
[19] Shapiro C. and Stiglitz J. [1984] Equilibrium unemployment as a worker discipline device. American Economic Review. 74, 433-444.

[20] Siebert H. [1997] Labor Market Rigidities: At the Root of Unemployment in Europe. Journal of Economic Perspectives 11(3), 37-54. 


\section{A Appendix 1: uniqueness of the macroeconomic}

\section{equilibrium}

To define the equilibrium solution, a second expression for relative employment can be derived from (18). Substituting (21) for $P_{G}$, one obtains: $\alpha_{G} \cdot\left(\frac{1+(\alpha \cdot l)^{\frac{1-\eta}{\eta}}}{2}\right)^{\frac{1}{\eta-1}} \cdot\left(1-\frac{1}{\eta}\right)=$ $\frac{a+p+r+x}{x} \cdot e$ from which the following expression for relative employment $l$ can be derived: $l_{2}(a, \eta) \equiv \frac{1}{\alpha} \cdot\left[2 \cdot\left[\frac{e \cdot(a+x+r+p) \cdot \eta}{x \cdot \alpha_{G} \cdot(\eta-1)}\right]^{\eta-1}-1\right]^{\frac{\eta}{1-\eta}}$. One can show that $\frac{\partial l_{2}}{\partial \eta}>0$ and $\frac{\partial l_{2}}{\partial a}<0 .{ }^{15}$

The equilibrium can now be deduced from the condition: $l_{1}(a, \eta, F)=l_{2}(a, \eta)$. $l_{1}(a, \eta, F)$ defines an increasing schedule in the $(a, l)$ plane whereas $l_{2}(a, \eta)$ is characterised by a decreasing schedule. We can therefore express conditions for the existence and uniqueness of the equilibrium in the following proposition.

Proposition 3 There exists a unique equilibrium for the model if

$$
\begin{aligned}
& 2 \cdot\left(\frac{\eta \cdot(\alpha \cdot(e \cdot(r+x)-F \cdot(p+r) \cdot x))}{x \cdot \alpha_{G} \cdot(\eta-1)}\right)^{\eta-1}-\left(\frac{\alpha \cdot(e \cdot(r+x)-F \cdot(p+r) \cdot x)}{e \cdot(p+r+x)}\right)^{\eta-1}>1 \\
& \text { and } 1>2 \cdot\left(\frac{\eta \cdot(\alpha \cdot(e \cdot(1+r+x)-F \cdot(p+r) \cdot x))}{x \cdot \alpha_{G} \cdot(\eta-1)}\right)^{\eta-1}-\left(\frac{\alpha \cdot(e \cdot(1+r+x)-F \cdot(p+r) \cdot x)}{e \cdot(1+p+r+x)}\right)^{\eta-1}
\end{aligned}
$$

Proof. The first condition ensures that when $a=0, l_{2}(e \cdot(x+r+p), \eta)>l_{1}(e \cdot(x+r+p), \eta)$; the second condition implies that $l_{2}(e \cdot(1+x+r+p), \eta)<l_{1}(e \cdot(1+x+r+p), \eta)$ when $a=1 . l_{2}(a, \eta)$ being a decreasing function of $a, l_{1}(a, \eta, F)$ an increasing function, there exists a unique $a$ which identifies a solution $a(\eta, F) \in] 0,1\left[\right.$. The solution for $a^{*}$ is given by the value which solves the following equality: $\left(\frac{e \cdot(a+x+r+p)}{e \cdot(a+x+r+p)-e \cdot p-x \cdot(p+r) \cdot F} \cdot \frac{1}{\alpha}\right)^{\eta-1}=$ $2\left(\frac{e \cdot(a+x+r+p)}{x \cdot \alpha_{G}} \cdot \frac{\eta}{\eta-1}\right)^{\eta-1}-1$

Proof of Proposition 1. 
Proof. Since $q=1-\frac{1}{l}$, the result immediately derives from the shifts of the $l(a, \eta, F)$ and $l_{2}(a, \eta)$ curves when competition increases. Another way to prove the result is the following. If we denote by $*$ either of the two variables $\eta$ and $F$, we can note that $\frac{d l_{1}}{d *}=$ $\frac{\partial l_{1}}{\partial *}+\frac{\partial l_{1}}{\partial a} \cdot \frac{d a}{d *}=\frac{\partial l_{1}}{\partial *}+\frac{\partial l_{1}}{\partial a} \cdot\left(\frac{-\frac{\partial l_{1}}{\partial *}+\frac{\partial l_{2}}{\partial *}}{\frac{\partial l_{1}}{\partial a}-\frac{\partial l_{2}}{\partial a}}\right)$. This can be rearranged as $\frac{\frac{\partial l_{1}}{\partial a} \cdot \frac{\partial l_{2}}{\partial *}-\frac{\partial l_{1}}{\partial *} \cdot \frac{\partial l_{2}}{\partial a}}{\frac{\partial l_{1}}{\partial a}-\frac{\partial l_{2}}{\partial a}}$. Since $\frac{\partial l_{1}}{\partial a}>0$ and $\frac{\partial l_{2}}{\partial a}<0$, the sign of the derivative is given by $\frac{\partial l_{1}}{\partial a} \cdot \frac{\partial l_{2}}{\partial *}-\frac{\partial l_{1}}{\partial *} \cdot \frac{\partial l_{2}}{\partial a}$. Since $\frac{\partial l_{1}}{\partial \eta}>0$ and $\frac{\partial l_{2}}{\partial \eta}>0$, it immediately follows that $\frac{d l}{d \eta}>0$. On the other hand, as $\frac{\partial l_{1}}{\partial F}<0$ and $\frac{\partial l_{2}}{\partial F}=0$, one can conclude that $\frac{d l}{d F}<0$.

\section{Proof of Proposition 2.}

Proof. We already know that the solution for $a^{*}$ is identified by the value solving $\left(\frac{e \cdot(a+x+r+p)}{e \cdot(a+x+r+p)-e \cdot p-x \cdot(p+r) \cdot F} \cdot \frac{1}{\alpha}\right)^{\eta-1}=2\left(\frac{e \cdot(a+x+r+p)}{x \cdot \alpha_{G}} \cdot \frac{\eta}{\eta-1}\right)^{\eta-1}-1$. Denoting $S_{1}(a, \eta, F) \equiv$ $\left(\frac{e \cdot(a+x+r+p)}{e \cdot(a+x+r+p)-e \cdot p-x \cdot(p+r) \cdot F} \cdot \frac{1}{\alpha}\right)^{\eta-1}$ and $S_{2}(a, \eta) \equiv 2\left(\frac{e \cdot(a+x+r+p)}{x \cdot \alpha_{G}} \cdot \frac{\eta}{\eta-1}\right)^{\eta-1}-1$, one has $\frac{d a}{d *}=-\frac{\frac{\partial S_{1}}{\partial *}-\frac{\partial S_{2}}{\partial *}}{\frac{\partial S_{1}}{\partial s}-\frac{\partial S_{2}}{\partial s}}$. From the price setting equations we know that $\frac{e \cdot(a+x+r+p)}{e \cdot(a+x+r+p)-e \cdot p-x \cdot(p+r) \cdot F} \cdot$ $\frac{1}{\alpha}<1$ and $\frac{e \cdot(a+x+r+p)}{x \cdot \alpha_{G}} \cdot \frac{\eta}{\eta-1}<1$. It can easily be shown that $\frac{\partial S_{1}}{\partial s}<0$ and $\frac{\partial S_{2}}{\partial s}>0$. The sign of $\frac{d a}{d *}$ thus depends on the sign of $\frac{\partial S_{1}}{\partial *}-\frac{\partial S_{2}}{\partial *}$. One can easily see that $\frac{\partial S_{1}}{\partial F}>0$ while $\frac{\partial S_{2}}{\partial F}=0$; this clearly implies that $\frac{d a}{d F}>0$. On the other hand, one should further note that both $S_{1}(a, \eta, F)$ and $S_{2}(a, \eta)$ are monotonically decreasing functions of $\eta$ (that is, $\frac{\partial S_{1}}{\partial \eta}<0$ and $\left.\frac{\partial S_{2}}{\partial \eta}<0\right)$; moreover $S_{1}(a, \infty, F)=0>-1=S_{2}(a, \infty)$. Therefore, for the two curves to cross and define a positive integer $a(\eta, F)$ the following condition must hold: $\frac{\partial S_{1}}{\partial \eta}>\frac{\partial S_{2}}{\partial \eta}$ as illustrated in Figure1 below. This means that $\frac{d a}{d \eta}>0$.

\section{FIGURE 1}

Proof of complementarity across policies.

$$
\frac{\partial^{2} a}{\partial \eta \partial F}=\frac{\frac{\partial^{2} S_{1}}{\partial \eta \partial F} \cdot\left(\frac{\partial S_{2}}{\partial a}-\frac{\partial S_{1}}{\partial a}\right)+\frac{\partial^{2} S_{1}}{\partial a \partial F} \cdot\left(\frac{\partial S_{1}}{\partial \eta}-\frac{\partial S_{2}}{\partial \eta}\right)}{\left(\frac{\partial S_{2}}{\partial a}-\frac{\partial S_{1}}{\partial a}\right)^{2}}<0 \text { as one can show that } \frac{\partial^{2} S_{1}}{\partial \eta \partial F}<0 \text { and }
$$
$\frac{\partial^{2} S_{1}}{\partial a \partial F}<0$. 


$$
\begin{aligned}
& \frac{\partial^{2} l}{\partial \eta \partial F}=\frac{\partial^{2} l_{1}(a, \eta, F)}{\partial \eta \partial F}+\frac{\partial^{2} l_{1}(a, \eta, F)}{\partial a \partial F} \cdot a_{\eta}+\frac{\partial l_{1}(a, \eta, F)}{\partial a} \cdot \frac{\partial^{2} a}{\partial \eta \partial F}<0 \text { as it can be proved that } \\
\frac{\partial^{2} l_{1}(a, \eta, F)}{\partial \eta \partial F} & <0 \text { and } \frac{\partial^{2} l_{1}(a, \eta, F)}{\partial a \partial F}<0 . \\
& \left|\frac{\partial^{2} l}{\partial \eta \partial F}\right|>\left|\frac{\partial^{2} a}{\partial \eta \partial F}\right| \text { in fact: } \\
& \frac{\partial^{2} l}{\partial \eta \partial F}-\frac{\partial^{2} a}{\partial \eta \partial F}=\frac{\partial^{2} l_{1}(a, \eta, F)}{\partial \eta \partial F}+\frac{\partial^{2} l_{1}(a, \eta, F)}{\partial a \partial F} \cdot a_{\eta}+\left(\frac{\partial l_{1}(a, \eta, F)}{\partial a}-1\right) \cdot \frac{\partial^{2} a}{\partial \eta \partial F}<0 \text { as } \frac{\partial l_{1}(a, \eta, F)}{\partial a}-1>
\end{aligned}
$$

0 .

\section{B Appendix 2: an exemple of complementarity}

\section{between increased competition and firing costs}

In order to run simulations, we first solve for an explicit value of $a^{*}$ by linearizing $\left(\frac{e \cdot(a+x+r+p)}{e \cdot(a+x+r+p)-e \cdot p-x \cdot(p+r) \cdot F} \cdot \frac{1}{\alpha}\right.$ $2 \cdot\left(\frac{e \cdot(a+x+r+p)}{x \cdot \alpha_{G}} \cdot \frac{\eta}{\eta-1}\right)^{\eta-1}-1$ through a first degree expansion around $\{p=0, r=0\}$. We then plug the value of $a^{*}$ into $l_{1}(a, \eta)$ to obtain $l^{*}$. The simulations that follow use the following parameters values: $N=1, p=0.03, x=0.4, r=0.07, \alpha_{B}=1.6-\delta$, $\alpha_{G}=1.6+\delta$. Results are presented below. The variables $\eta>1$ and $1>F>0$ appear respectively on the right-hand and left-hand axis in all figures.

The results for a relatively small $\delta$ are the following:

$\delta=0.07$

\section{FIGURE 2}

FIGURE 3

Results for a higher $\delta$ are:

$\delta=0.12$

FIGURE 4

FIGURE 5 
Figures

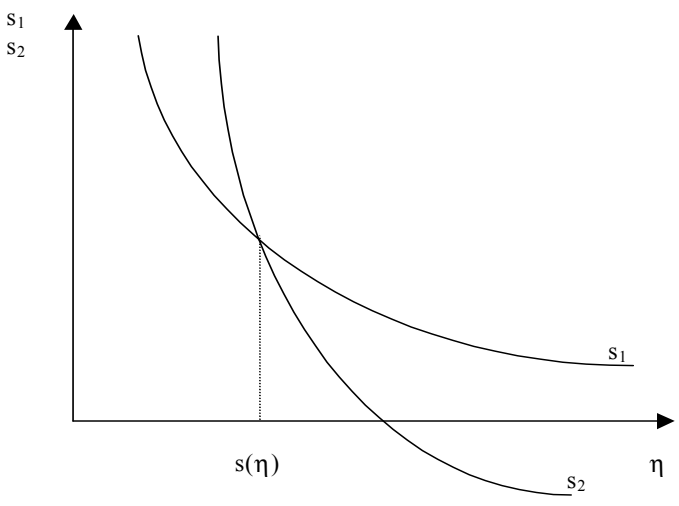

Figure 1. Defining $s(\eta)$ 


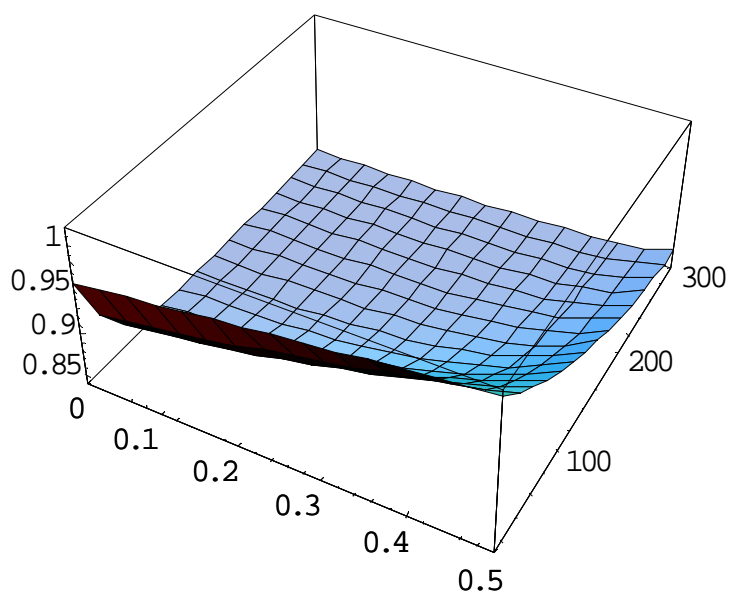

Figure 2. Employment

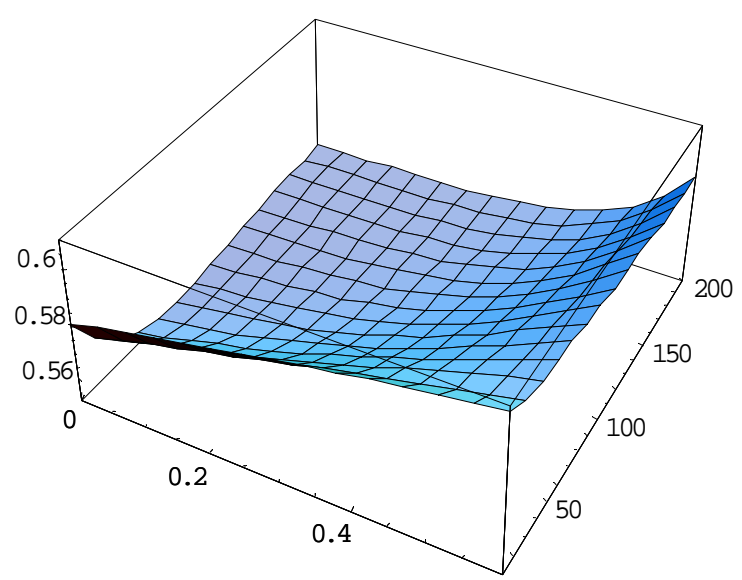

Figure 3. Welfare

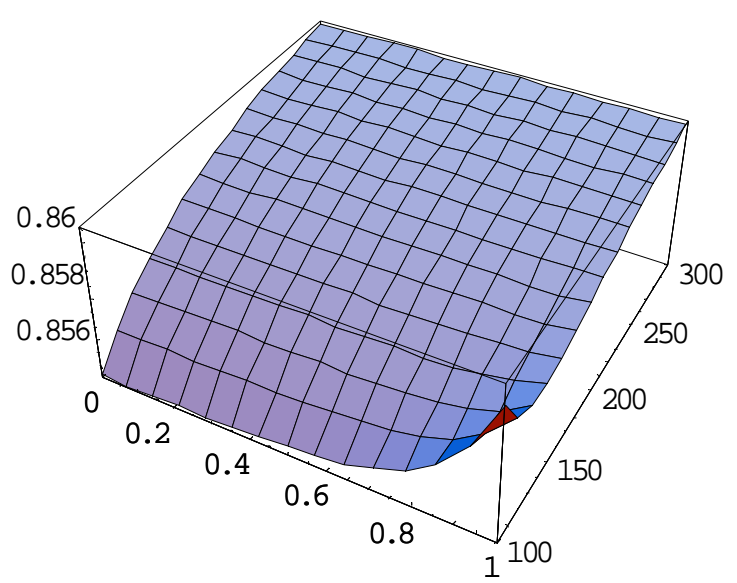

Figure 4. Employment 


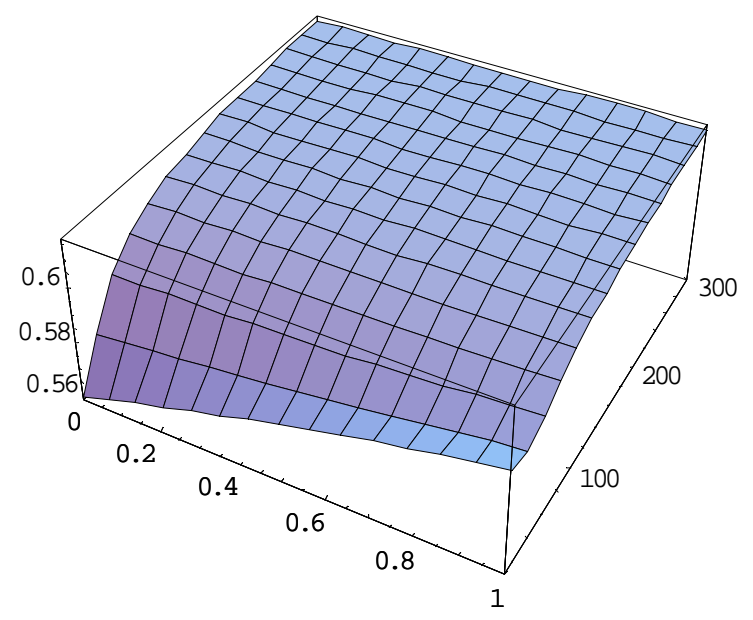

Figure 5. Welfare 


\section{Notes}

1. Nickell[1997] and Siebert [1997].

2 OECD [1994], [1997].

3 Coe and Snower [1997], Orszag and Snower [1998], Saint-Paul [2000].

4 Boeri et al. [2000], Nickell [1999], Nicoletti et al. [2000], Gersbach [1999] and [2000], Blanchard and Giavazzi [2003].

5 This is in line with results provided by Fella [2000]

6 We assume that the number of firms is large enough. This also means that firms will not consider the impact on the aggregate price index, when maximising profits.

7 i.e. the consumption level of the final good

8 As in Fella [2000] or Amable and Gatti [2004].

9 In fact, one can show that $V_{S}^{G}=V_{N S}^{G} \rightarrow x \cdot\left(U_{t}-V^{G}\right)=-e$ and $V_{S}^{B}=V_{N S}^{B} \rightarrow$ $x \cdot\left(U_{t}-V^{B}\right)=-e$; this implies that the arbitrage condition always holds at the equilibrium.

10 One should further note that the set-up of the model implies profits and wages being entirely spent in consumption of the final good.

11 Bertola [1990].

12 See Amable and Gatti [2004]

13 In fact, $\frac{\partial l_{2}}{\partial s}<0$ if $1-2 \cdot\left(\frac{s \cdot \eta}{x \cdot \alpha_{G} \cdot(\eta-1)}\right)^{\eta-1}<0$, while $\frac{\partial l_{2}}{\partial s}>0$ corresponds to $-1+2 \cdot x^{1-\eta} \cdot s^{-1+\eta} \cdot \alpha_{G}^{1-\eta} \cdot\left(\frac{-1+\eta}{\eta}\right)^{1-\eta}<0$, in which case $l_{2}(s, \eta)$ is only defined for $\eta=2$. Therefore, for non complex solutions of $l_{2}(s, \eta)$, one has $\frac{\partial l_{2}}{\partial s}<0$. 